\title{
Oxymatrine alleviates periodontitis in rats by inhibiting inflammatory factor secretion and regulating MMPs/ TIMP protein expression ${ }^{1}$
}

Ni Deng', Lili Xie", Yongwei Li"', Haishu Lin"', Renhui Luo'v

'MS, Department of Stomatology, Hainan General Hospital, Haikou, China. Acquisition of data, critical revision, final approval.

"MS, Department of Stomatology, Hainan General Hospital, Haikou, China. Statistical analysis, critical revision, final approval.

'"MS, Department of Stomatology, Hainan General Hospital, Haikou, China. Design of the study, critical revision, final approval.

IVMS, Department of Stomatology, Guangzhou Hospital of Integrated Traditional and Western Medicine, Guangzhou, China. Design of the study, critical revision, final approval.

\section{Abstract}

Purpose: To investigate the effect of oxymatrine on periodontitis in rats and related mechanism.

Methods: Ninety SD rats were divided into control, model, 10,20 and $40 \mathrm{mg} / \mathrm{kg}$ oxymatrine and tinidazole groups. The periodontitis model was established in later 5 groups. The 10, 20 and $40 \mathrm{mg} / \mathrm{kg}$ oxymatrine groups were intragastrically administrated with 10,20 and $40 \mathrm{mg} /$ $\mathrm{kg}$ oxymatrine, respectively. The tinidazole group was intragastrically administrated with 100 $\mathrm{mg} / \mathrm{kg}$ tinidazole. The treatment duration was 4 weeks. The tooth mobility, gingival and plaque indexes, serum inflammatory factor levels and gingival tissue matrix metalloproteinases (MMPs) and tissue inhibitor of metalloproteinase (TIMP) protein levels were detected.

Results: After treatment, compared with model group, in $40 \mathrm{mg} / \mathrm{kg}$ oxymatrine group the rat general conditions were obviously improved, the tooth mobility, gingival index and plaque index were significantly decreased $(P<0.05)$, the serum tumor necrosis factor- $\alpha$, interleukin$1 \beta$ and prostaglandin $E_{2}$ levels were significantly decreased $(P<0.05)$, the MMP-2 and MMP9 protein levels were significantly decreased $(P<0.05)$, and the TIMP-2 protein level was significantly increased $(P<0.05)$.

Conclusions: Oxymatrine can alleviate the experimental periodontitis in rats. The mechanism may be related to its inhibiting inflammatory factor secretion and regulating MMPs/TIMP protein expression.

Key words: Periodontitis. Matrix Metalloproteinases. Rats. 


\section{- Introduction}

Periodontitis is a chronic infectious disease occurring in the periodontal support tissue, which can cause the periodontal support tissue inflammation, periodontal pocket formation, progressive attachment loss and alveolar bone resorption, eventually leading to the tooth loosening and extraction ${ }^{1}$. Periodontitis is the primary cause of tooth loss in adults. The oral plaque is the main pathogenic factor of periodontitis. The plaque induces the early inflammation, and the host's defense response to plaque bacteria further promotes the periodontal connective tissue destruction and alveolar bone resorption ${ }^{2}$. The key of successful prevention and treatment of periodontitis is to control bacteria and their products in periodontal tissues and gingival crevicular fluid, so as to maintain the microecological balance of periodontal local environment ${ }^{3}$. The plaque is usually removed using mechanical methods, but this can more or less cause the mechanical damage to tooth surface. At present, the antibiotics treatment is mostly used for treating periodontitis, and the short-term effect is obvious. However, the periodontitis is easy to recur, and many side effects are easy to produce. In addition, in recent years the resistance of pathogenic microorganisms to antibiotics has been increasing due to the misuse, and the efficacy of antibiotics treatment has been declining $^{4}$. It is reported that, the inflammatory response and changes in expression of matrix metalloproteinases (MMPs) and tissue inhibitor of metalloproteinases (TIMPs) are involved in the occurrence and development of periodontitis ${ }^{5-7}$. Oxymatrine is the main component of alkaloids in medical plant Sophora alopecuroides, Sophora flavescens and Sophora japonica. The pharmacological and clinical studies have found that, oxymatrine has antiviral, anti-inflammatory, anti-tumor, sedative, analgesic, antipyretic, hypothermic, cardiotonic, hypotensive and anti-arrhythmic effects $^{8-11}$. Various preparations of oxymatrine have been widely used in clinical practice. However, there is no report on the effect of oxymatrine on periodontitis. In this study, the effects of oxymatrine on periodontitis in rats and the mechanisms related to inflammatory response and MMPs/TIMP expression were investigated. The objective was to provide an experimental basis for the clinical application of oxymatrine to treatment of periodontitis.

\section{Methods}

This study was performed in strict accordance with the recommendations in the Guide for the Care and Use of Laboratory Animals of the National Institutes of Health. The animal use protocol has been reviewed and approved by the Institutional Animal Care and Use Committee of Hainan General Hospital.

\section{Establishment of periodontitis model}

According to the reported method ${ }^{12}$ with some modifications, ninety SD rats $(8$ weeks age; $280 \pm 30 \mathrm{~g}$; male and female in half; Hainan Experimental Animal Center, Haikou, China) were randomly divided into 6 groups: control group, model group, 10, 20 and $40 \mathrm{mg} /$ kg oxymatrine groups and tinidazole group, 15 rats in each group. In later 5 groups, the periodontitis model was established. The rats were anaesthetized by intraperitoneal injection of $10 \%$ chloral hydrate with dose of $3 \mathrm{ml} / \mathrm{kg}$. The neck of left maxillary first molar was ligated using $0.2 \mathrm{~mm}$-diameter orthodontic wire. Then, the rats were daily fed with $50 \mathrm{ml} 10 \%$ sugar water instead of drinking water. From the second day after ligation, the prednisolone acetate was injected into the four muscles of hind legs, with dose of $5 \mathrm{mg} / \mathrm{kg}$. The injection 
was performed once every two days, for 20 days. During the modeling period, no rat died.

\section{Treatment method}

After establishment of periodontitis model, the rats were fed normally for 1 week. Then, the ligature wire was removed. The rats in 10,20 and $40 \mathrm{mg} / \mathrm{kg}$ oxymatrine groups were intragastrically administrated with oxymatrine (HPLC purity $\geq 98 \%$; Chengdu Deruike Biotechnology Co., Ltd., Chengdu, China), with dose of 10,20 and $40 \mathrm{mg} / \mathrm{kg}$, respectively. The rats in tinidazole group were intragastrically administrated with $100 \mathrm{mg} / \mathrm{kg}$ tinidazole. The rats in control and model groups were intragastrically administrated with normal saline. The treatment was performed once per day, for 4 weeks. During the treatment, all rats were fed with standard feed and free intake. The room temperature was $20-25^{\circ} \mathrm{C}$. The water drinking was forbidden for $2 \mathrm{~h}$ after treatment, with free drinking in the rest time. The conditions of rats were observed during the experiment.

\section{Measurement of tooth mobility}

The tooth mobility before and after treatment was measured by scoring as follows: only buccal-lingual loosening, 1 point; buccallingual loosening and mesiodistal loosening, 2 points; buccal-lingual loosening, mesiodistal loosening and vertical loosening, 3 points ${ }^{13}$.

\section{Measurement of gingival index}

Gingival index was measured by scoring as follows: 0 point: normal gingiva; 1 point: slightly edema of gingiva, without bleeding on probing; 2 points: slightly edema of gingiva, with bleeding on probing; 3 points: edema of gingiva, with spontaneous bleeding or ulcer formation. Four positions including proximal nipple, distal nipple, central nipple and palatal surface of buccal surface of the experimental tooth were examined. The mean value of score of four positions was calculated as the gingival index.

\section{Measurement of plaque index}

A drop of plaque stain ( $2 \%$ erythrosine sodium) was applied to the experimental tooth. After 30s, the tooth was rinsed with water for 10s. The area and depth of purple-red on the teeth were observed. The plaque index was measured by scoring as follows: 0 point: no plaque; 1 point: there were scattered spots on the gingival margin of tooth neck; 2 points: there was continuous narrow-banded plaque on the tooth neck, with width no more than $1 \mathrm{~mm}$; 3 points: the width of plaque was more than $1 \mathrm{~mm}$, but the coverage area was less than $1 / 3$ of tooth crown; 4 points: the coverage area of plaque was from $1 / 3$ to $2 / 3$ of tooth crown; 5 points: the coverage area of plaque was no less than $2 / 3$ of tooth crown.

\section{Determination of serum inflammatory factor levels}

The rats were anesthetized with 5\% chloral hydrate. Five milliliter of blood was taken from abdominal aorta. After centrifuging at $2000 \mathrm{r} / \mathrm{min}$ for $10 \mathrm{~min}$, the supernatant was obtained. The serum levels of inflammatory factor tumor necrosis factor- $\alpha$ (TNF- $\alpha$ ); interleukin-1 $\beta$ (IL-1 $\beta$ ) and prostaglandin $E_{2}$ $\left(P G E_{2}\right)$ were determined by enzyme linked immunosorbent assay. The process was according to the instructions of the kits.

Determination of matrix metalloproteinase and inhibitor of metalloproteinase levels in gingival tissue

Ten gram of gingival tissue was taken and homogenized. The protein was extracted using and cell lysate, and the concentration was 
determined using BCA protein quantitation kit. The expressions levels of MMP-2, MMP-9 and TIMP-2 protein in gingival tissue were detected using western blot assays. $\beta$-actin was used as the internal reference. The relative expression level of target protein was calculated by the ratio of integral optical density of target protein to $\beta$-actin. The experiment procedures were in accordance to the instructions of kits.

\section{Statistical analysis}

Statistical analysis was performed using SPSS 20.0 software (SPSS Inc., Chicago, IL, USA). The data were presented as mean $\pm S D$. The difference among different groups was analyzed using one-way analysis of variance with $q$ test. $P<0.05$ was defined as statistically significant.

\section{Results}

\section{General conditions of rats after treatment}

After treatment, the spirit, activity, hair, food intake, stool, weight, periodontal tissues color and shape in control group were normal, with no obvious difference than before treatment. In model group, compared with before treatment, after treatment the spirit, activity, hair, food intake and stool were worsened, with decreased weight and obvious gingival gingival swelling and congestion. Compared with model group, the general conditions in other 4 groups were improved, especially in $40 \mathrm{mg} / \mathrm{kg}$ oxymatrine and tinidazole groups.

\section{Change of tooth mobility}

Before treatment, there was no significant difference of tooth mobility score among model, $10 \mathrm{mg} / \mathrm{kg}$ oxymatrine, $20 \mathrm{mg} /$ $\mathrm{kg}$ oxymatrine, $40 \mathrm{mg} / \mathrm{kg}$ oxymatrine and tinidazole groups $(P>0.05)$. After treatment, the tooth mobility score in model group was $2.32 \pm 0.41$ points. The tooth mobility scores in $40 \mathrm{mg} / \mathrm{kg}$ oxymatrine and tinidazole groups were $1.38 \pm 0.33$ and $1.33 \pm 0.23$ points, respectively, which were significantly lower than those in model group, respectively $(\mathrm{P}<0.05)$ (Table 1).

Table 1 - Change of tooth mobility score in different groups (points).

\begin{tabular}{lll} 
Group & $\begin{array}{l}\text { Before } \\
\text { treatment }\end{array}$ & $\begin{array}{l}\text { After } \\
\text { treatment }\end{array}$ \\
\hline $\begin{array}{l}\text { Model } \\
10 \mathrm{mg} / \mathrm{kg}\end{array}$ & $2.33 \pm 0.31$ & $2.32 \pm 0.41$ \\
oxymatrine & $2.31 \pm 0.32$ & $2.21 \pm 0.42$ \\
$\begin{array}{l}20 \mathrm{mg} / \mathrm{kg} \\
\text { oxymatrine }\end{array}$ & $2.28 \pm 0.28$ & $2.04 \pm 0.51$ \\
$\begin{array}{l}40 \mathrm{mg} / \mathrm{kg} \\
\text { oxymatrine }\end{array}$ & $2.27 \pm 0.34$ & $1.38 \pm 0.33^{\mathrm{bcd}}$ \\
Tinidazole & $2.32 \pm 0.37$ & $1.33 \pm 0.23^{\mathrm{bcd}}$ \\
\hline
\end{tabular}

${ }^{\mathrm{b}} \mathrm{P}<0.05$ compared with model group; ${ }^{\mathrm{C}} \mathrm{P}<0.05$ compared with $10 \mathrm{mg} / \mathrm{kg}$ oxymatrine group; ${ }^{\mathrm{d}} \mathrm{P}<0.05$ compared with $20 \mathrm{mg} / \mathrm{kg}$ oxymatrine group.

\section{Gingival index and plaque index after treatment}

As shown in Table 2, after treatment, the gingival index and plaque index in model group were $3.46 \pm 0.75$ and $4.22 \pm 0.72$ points, respectively, which were significantly higher than $1.54 \pm 0.36$ and $2.55 \pm 0.45$ points in control group, respectively $(P<0.05)$. The gingival index and plaque index in $40 \mathrm{mg} / \mathrm{kg}$ oxymatrine group were $1.95 \pm 0.47$ and $2.99 \pm 0.63$ points, respectively, and those in tinidazole group were $1.67 \pm 0.61$ and $2.78 \pm 0.82$ points, respectively. Compared with model group, the gingival index and plaque index in $40 \mathrm{mg} / \mathrm{kg}$ oxymatrine and tinidazole groups were significantly decreased, respectively $(\mathrm{P}<0.05)$ (Table 2$)$. 
Table 2 - Gingival index and plaque index after treatment in different groups (points).

\begin{tabular}{lll}
\hline Group & Gingival index & Plaque index \\
\hline Control & $1.54 \pm 0.36$ & $2.55 \pm 0.45$ \\
Model & $3.46 \pm 0.75^{\mathrm{a}}$ & $4.22 \pm 0.72^{\mathrm{a}}$ \\
$10 \mathrm{mg} / \mathrm{kg}$ oxymatrine & $3.01 \pm 0.72^{\mathrm{a}}$ & $4.45 \pm 0.82^{\mathrm{a}}$ \\
$20 \mathrm{mg} / \mathrm{kg}$ oxymatrine & $2.48 \pm 0.67^{\mathrm{a}}$ & $3.54 \pm 0.72^{\mathrm{a}}$ \\
$40 \mathrm{mg} / \mathrm{kg}$ oxymatrine & $1.95 \pm 0.47^{\mathrm{bc}}$ & $2.99 \pm 0.63^{\mathrm{bc}}$ \\
Tinidazole & $1.67 \pm 0.61^{\mathrm{bcd}}$ & $2.78 \pm 0.82^{\mathrm{bc}}$ \\
\hline
\end{tabular}

${ }^{a} \mathrm{P}<0.05$ compared with control group; ${ }^{\mathrm{b}} \mathrm{P}<0.05$ compared with model group; ${ }^{\mathrm{C}}<0.05$ compared with $10 \mathrm{mg} / \mathrm{kg}$ oxymatrine group; ${ }^{\mathrm{d} P}<0.05$ compared with $20 \mathrm{mg} / \mathrm{kg}$ oxymatrine group.

Serum TNF- $\alpha$, IL-16 and PGE $_{2}$ levels after treatment

After treatment, the serum TNF- $\alpha$, IL-1 $\beta$ and $\mathrm{PGE}_{2}$ levels in model group were $4.88 \pm 0.84,0.35 \pm 0.06$ and $9.34 \pm 2.05 \mathrm{pg} / \mathrm{ml}$, respectively, which were significantly higher than $3.52 \pm 0.67,0.12 \pm 0.04$ and $3.45 \pm 0.79 \mathrm{pg} /$ $\mathrm{ml}$ in control group, respectively $(\mathrm{P}<0.05)$. The serum TNF- $\alpha, \mathrm{IL}-1 \beta$ and PGE 2 levels in 20 $\mathrm{mg} / \mathrm{kg}$ oxymatrine, $40 \mathrm{mg} / \mathrm{kg}$ oxymatrine and tinidazole groups were $3.87 \pm 0.87,0.20 \pm 0.05$ and $7.21 \pm 1.65 \mathrm{pg} / \mathrm{ml}, 3.72 \pm 0.65,0.15 \pm 0.03$ and $6.02 \pm 1.37 \mathrm{pg} / \mathrm{ml}$, and $3.64 \pm 0.72,0.18 \pm 0.04$ and $5.77 \pm 1.86 \mathrm{pg} / \mathrm{ml}$, respectively. Each index in $20 \mathrm{mg} / \mathrm{kg}$ oxymatrine, $40 \mathrm{mg} / \mathrm{kg}$ oxymatrine and tinidazole groups was significantly lower than that in model group, respectively $(\mathrm{P}<0.05)$ (Figure 1).
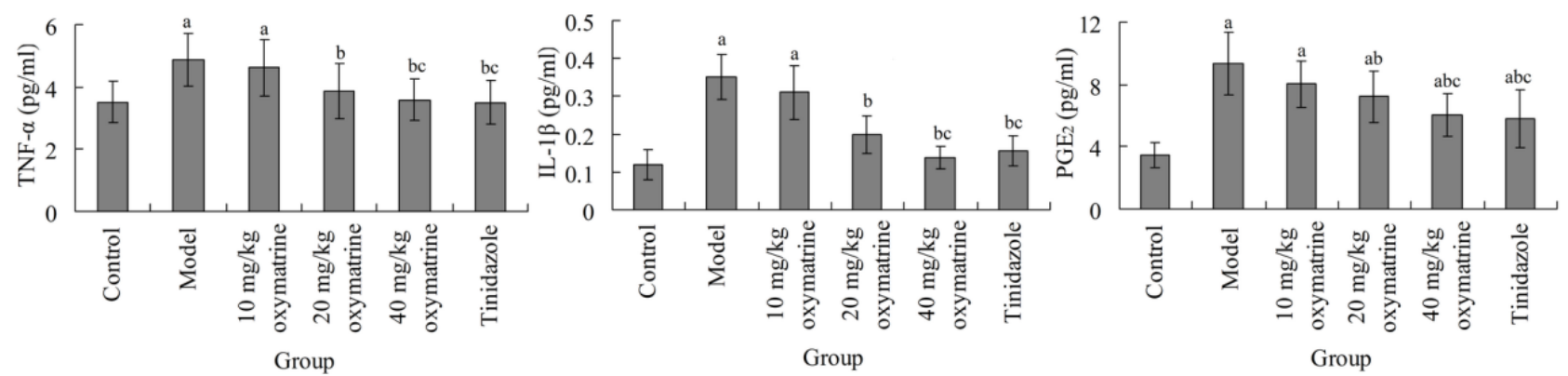

Figure 1 - Serum TNF- $\alpha, \mathrm{IL}-1 \beta$ and $\mathrm{PGE}_{2}$ levels in different groups. ${ }^{\mathrm{a}} \mathrm{P}<0.05$ compared with control group; ${ }^{\mathrm{b}} \mathrm{P}<0.05$ compared with model group; ${ }^{\mathrm{C}} \mathrm{P}<0.05$ compared with $10 \mathrm{mg} / \mathrm{kg}$ oxymatrine group. TNF- $\alpha$, tumor necrosis factor- $\alpha$; IL-1 $\beta$, interleukin-1 $\beta$; PGE $E_{2}$, prostaglandin $E_{2}$.

Gingival tissue MMP-2, MMP-9 and TIMP-2 protein levels after treatment

After treatment, the gingival tissue MMP-2 and MMP-9 protein levels in model group (MMP-2/ $\beta$-actin, $1.56 \pm 0.46$; MMP-9/ $\beta$ actin, $1.23 \pm 0.33$ ) were significantly higher than those in control group (MMP-2/ $\beta$-actin,
0.71 $\pm 0.13 ; \quad M M P-9 / \beta$-actin, $\quad 0.52 \pm 0.09)$, respectively $(\mathrm{P}<0.05)$, and the TIMP-2 protein level in model group (TIMP-2/ $\beta$-actin, $0.42 \pm 0.09)$ was significantly lower than that in control group (TIMP-2/ $\beta$-actin, $0.84 \pm 0.15$ ) $(P<0.05)$. Compared with model group, the MMP-2 and MMP-9 protein levels in $40 \mathrm{mg} / \mathrm{kg}$ oxymatrine group (MMP-2/ $\beta$-actin, 0.92 \pm 0.21 ; 
MMP-9/ $\beta$-actin, $0.71 \pm 0.15)$ and tinidazole group (MMP-2/ $\beta$-actin, $0.83 \pm 0.22 ; \mathrm{MMP}-9 / \beta$ actin, $0.65 \pm 0.13)$ were significantly decreased, respectively $(\mathrm{P}<0.05)$, and the TIMP-2 protein levesl in $40 \mathrm{mg} / \mathrm{kg}$ oxymatrine group (TIMP$2 / \beta$-actin, $0.62 \pm 0.19)$ and tinidazole group (TIMP-2/ $\beta$-actin, $0.65 \pm 0.21$ ) were significantly increased, respectively $(\mathrm{P}<0.05)$ (Figure 2$)$.
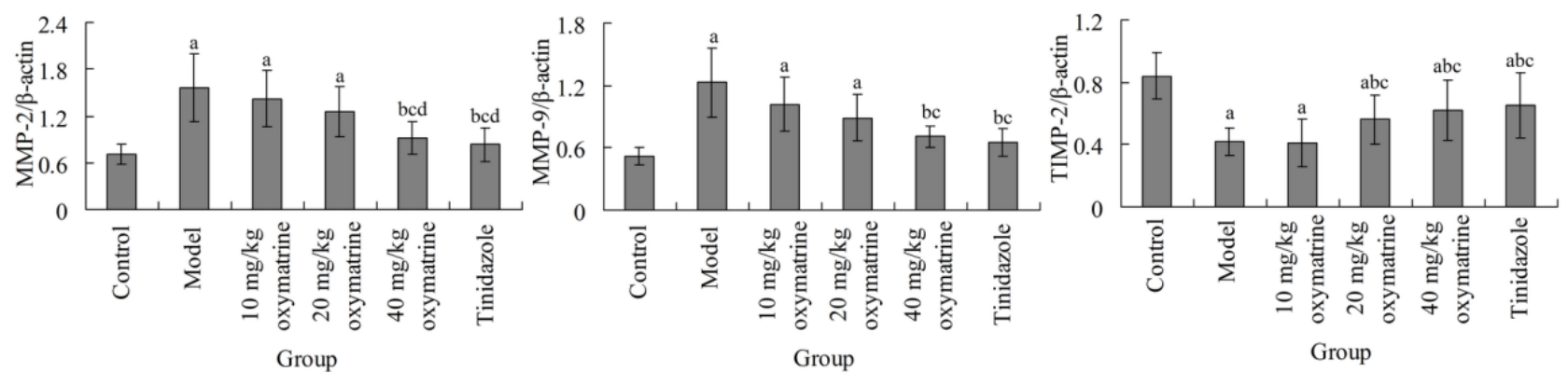

Figure 2 - Gingival tissue MMP-2, MMP-9 and TIMP-2 protein levels after treatment in different groups. ${ }^{a} \mathrm{P}<0.05$ compared with control group; ${ }^{\mathrm{b}} \mathrm{P}<0.05$ compared with model group; ${ }^{\mathrm{C}} \mathrm{P}<0.05$ compared with $10 \mathrm{mg} /$ kg oxymatrine group. MMP-2, matrix metalloproteinase-2; MMP-9, matrix metalloproteinase-9; TIMP-2, tissue inhibitor of metalloproteinases-2.

\section{- Discussion}

In this study, the effects of oxymatrine on periodontitis in rats were investigated. Result showed that, after treatment, the general conditions of rats in model group were obviously worse than those in control group. In addition, there was obvious tooth mobility in model group. The gingival index and plaque index in model group were significantly higher than those in control group, respectively. Compared with model group, in treatment groups the general conditions of rats were improved, the tooth mobility was significantly decreased, and the gingival index and plaque index were significantly decreased. This suggests that, the oxymatrine can alleviate the experimental periodontitis in rats.

Periodontitis is an inflammatory infectious disease of dental support tissue caused by gram-negative anaerobic bacteria, flagella, spirochetes and other microorganisms. Bacteria and their toxic products, such as bacterial endotoxins and enzymes, can directly damage the periodontal epithelium and connective tissue ${ }^{14,15}$. At the same time, the host defense cells are activated, thus releasing cytokines such as TNF- $\alpha$ and IL-1 $\beta$. These cytokines activate the lymphocytes and act as many target cells. They mediate the inflammation that leads to the secondary injury of peripheral tissue ${ }^{16,17}$. TNF- $\alpha$ plays an important role in periodontal tissue destruction by stimulating collagenase-mediated tissue destruction, inducing osteoclast precursor cell proliferation and differentiation, and indirectly acting on mature osteoclasts to stimulate bone resorption ${ }^{18}$. IL-1 $1 \beta$ is a multifunctional cytokine and plays an active role in inflammation, immunity and bone metabolism. IL-1 $\beta$ can promote the bone resorption, and its level was significantly correlated with periodontal attachment loss ${ }^{19}$. PGE 2 is a very important inflammatory factor, and is also closely related to periodontitis ${ }^{20}$. Results of this study showed that, after treatment, the serum TNF- $\alpha$, IL-1 $\beta$ and $\mathrm{PGE}_{2}$ levels in model group were significantly higher than those in control group. This indicates that, the secretion of inflammatory factors is activated in periodontitis model. 
Compared with model group, the serum TNF- $\alpha, I L-1 \beta$ and PGE 2 levels in 20 and 40 $\mathrm{mg} / \mathrm{kg}$ oxymatrine groups were significantly decreased. This suggests that, oxymatrine can inhibit the secretion of inflammatory factors, thus alleviate the periodontitis.

MMPs are a family of proteolytic enzymes with similar structure and different functions. They can digest all the macromolecular substances outside the cells, and are the protease that mainly regulates the degradation of extracellular matrix $^{21,22}$. MMP-2 and MMP-9 are the main proteolytic enzymes in MMPs family, and belong to the gelatinases. MMP-2 is mainly expressed by gingival epidermal cells and periodontal ligament fibroblasts ${ }^{23}$. MMP9 is mainly produced by inflammatory cells infiltrating into periodontal tissues. The inflammatory cytokines can increase the synthesis and secretion of MMP-924. MMP-2 and MMP-9 are important biological markers of periodontitis. Their over-expressions are closely related to the degree of gingival fibrous matrix disintegration ${ }^{25}$. TIMPs are important factors regulating the activation of MMPs. TIMPs can reduce the excessive degradation of extracellular matrix by inactivating the activated $\mathrm{MMPs}^{26}$. TIMP-2 is an important member of TIMPs family, and is related to the development of periodontitis ${ }^{27}$. The regulation of MMPs/TIMPs is a new strategy for treating periodontitis. In this study, after treatment, the gingival tissue MMP-2 and MMP-9 protein levels in model group were significantly higher than those in control group, and the TIMP-2 protein level in model group was significantly lower than that in control group. Compared with model group, in $40 \mathrm{mg} / \mathrm{kg}$ oxymatrine group the MMP-2 and MMP-9 protein levels were significantly decreased, and the TIMP-2 protein level was significantly increased. This indicates that, oxymatrine can down-regulate the expression of MMP-2 and MMP-9 proteins and up-regulate the expression of TIMP-2 protein in periodontal tissues, which is related to its alleviation effect on periodontitis.

\section{Conclusions}

Oxymatrine can alleviate the experimental periodontitis in rats. The mechanism may be related to its inhibition of inflammatory factor secretion and regulating MMPs/TIMP protein expressions. This study has provided an experimental basis for the clinical application of oxymatrine to treatment of periodontitis. This study still has some limitations. Firstly, the sample size of this study is relatively small. Secondly, the correlations among different indexes have not been investigated. Thirdly, there may be other mechanisms of oxymatrine alleviating periodontitis. These issues should be solved in next studies.

\section{References}

1 Sidhu RK. Association between acute myocardial infarction and periodontitis: a review of the literature. J Int Acad Periodontol. 2016;18:23-33. PMID: 26764968.

2 Hajishengallis G. Periodontitis: from microbial immune subversion to systemic inflammation. Nat Rev Immunol. 2015;15:30-44. doi: 10.1038/nri3785.

3 Hu Z, Zhang Y, Li Z, Yu Y, Kang W, Han Y, Geng $X$, Ge S, Sun Y. Effect of Helicobacter pylori infection on chronic periodontitis by the change of microecology and inflammation. Oncotarget. 2016;7:66700-12. doi: 10.18632/oncotarget.11449.

4 Ardila CM, Granada MI, Guzmán IC. Antibiotic resistance of subgingival species in chronic periodontitis patients. J Periodontal Res. 2010;45:557-63. doi: 10.1111/j.16000765.2010.01274.x.

5 Boesing F, Patiño JS, da Silva VR, Moreira EA. The interface between obesity and periodontitis with emphasis on oxidative stress and inflammatory response. Obes Rev. 2009;10:290-7. doi: 10.1111/j.1467- 
789X.2008.00555.x.

6 Gonçalves PF, Huang H, McAninley S, Alfant B, Harrison P, Aukhil I, Walker C, Shaddox LM. Periodontal treatment reduces matrix metalloproteinase levels in localized aggressive periodontitis. J Periodontol. 2013;84:1801-8. doi: 10.1902/ jop.2013.130002.

7 Meschiari CA, Marcaccini AM, Santos Moura BC, Zuardi LR, Tanus-Santos JE, Gerlach RF. Salivary MMPs, TIMPs, and MPO levels in periodontal disease patients and controls. Clin Chim Acta. 2013;421:140-6. doi: 10.1016/j.cca.2013.03.008.

8 Wang YP, Zhao W, Xue R, Zhou ZX, Liu F, Han YX, Ren G, Peng ZG, Cen S, Chen HS, Li YH, Jiang JD. Oxymatrine inhibits hepatitis $B$ infection with an advantage of overcoming drug-resistance. Antiviral Res. 2011;89:22731. doi: 10.1016/j.antiviral.2011.01.005.

9 Liu Y, Xu Y, Ji W, Li X, Sun B, Gao Q, Su C. Anti-tumor activities of matrine and oxymatrine: literature review. Tumour Biol. 2014;35:5111-9. doi: 10.1007/s13277-0141680-z.

10 Yao N, Wang X. In vitro immunomodulatory activity of oxymatrine on Toll-like receptor 9 signal pathway in chronic hepatitis B. Am J Chin Med. 2014;42:1399-410. doi: 10.1142/ S0192415X14500888.

11 Cao YG, Jing S, Li L, Gao JQ, Shen ZY, Liu $Y$, Xing $Y, W u M L$, Wang $Y, X u C Q$, Sun HL. Antiarrhythmic effects and ionic mechanisms of oxymatrine from Sophora flavescens. Phytother Res. 2010;24:1844-9. doi: 10.1002/ptr.3206.

12 Di Paola R, Marzocco S, Mazzon E, Dattola F, Rotondo F, Britti D, De Majo M, Genovese $\mathrm{T}$, Cuzzocrea S. Effect of aminoguanidine in ligature-induced periodontitis in rats. J Dent Res. 2004;83:343-8. doi: 10.1177/154405910408300414.

13 Kawarizadeh A, Bourauel C, Jäger A. Experimental and numerical determination of initial tooth mobility and material properties of the periodontal ligament in rat molar specimens. Eur J Orthod. 2003;25:569-78. PMID: 14700262.

14 Thiha K, Takeuchi Y, Umeda M, Huang Y, Ohnishi M, Ishikawa I. Identification of periodontopathic bacteria in gingival tissue of Japanese periodontitis patients. Oral Microbiol Immunol. 2007;22:201-7. doi:
10.1111/j.1399-302X.2007.00354.x.

15 Graves DT, Kang J, Andriankaja O, Wada K, Rossa C Jr. Animal models to study host-bacteria interactions involved in periodontitis. Front Oral Biol. 2012;15:11732. doi: 10.1159/000329675.

16 Jiang ZL, Cui YQ, Gao R, Li Y, Fu ZC, Zhang B, Guan CC. Study of TNF- $\alpha$, IL-1 $\beta$ and LPS levels in the gingival crevicular fluid of a rat model of diabetes mellitus and periodontitis. Dis Markers. 2013;34:295-304. doi: 10.3233/ DMA-130974.

17 Wytrykowska A, Prosba-Mackiewicz $M$, Nyka WM. IL-1 $\beta$, TNF- $\alpha$, and IL-6 levels in gingival fluid and serum of patients with ischemic stroke. J Oral Sci. 2016;58:509-13. doi: 10.2334/josnusd.16-0278.

18 Liao CH, Fei W, Shen ZH, Yin MP, Lu C. Expression and distribution of TNF- $\alpha$ and PGE2 of periodontal tissues in rat periodontitis model. Asian Pac J Trop Med. 2014;7:412-6. doi: 10.1016/S19957645(14)60067-5.

19 Oh H, Hirano J, Takai H, Ogata Y. Effects of initial periodontal therapy on interleukin$1 \beta$ level in gingival crevicular fluid and clinical periodontal parameters. J Oral Sci. 2015;57:67-71. doi: 10.2334/josnusd.57.67.

20 Taxman DJ, Lei Y, Zhang S, Holley-Guthrie $E$, Offenbacher S, Ting JP. ASC-dependent RIP2 kinase regulates reduced PGE2 production in chronic periodontitis. J Dent Res. 2012;91:877-82. doi: 10.1177/0022034512454541.

21 Shi J, Son MY, Yamada S, Szabova L, Kahan S, Chrysovergis K, Wolf L, Surmak A, Holmbeck K. Membrane-type MMPs enable extracellular matrix permissiveness and mesenchymal cell proliferation during embryogenesis. Dev Biol. 2008;313:196209. doi: 10.1016/j.ydbio.2007.10.017.

22 Jabłońska-Trypuć $A$, Matejczyk $M$, Rosochacki S. Matrix metalloproteinases (MMPs), the main extracellular matrix (ECM) enzymes in collagen degradation, as a target for anticancer drugs. J Enzyme Inhib Med Chem. 2016;31:177-83. doi: 10.3109/14756366.2016.1161620.

23 Bătăiosu M, Taisescu Cl, Pisoschi CG, Pascu El, Juculină MJ, Dăguci L, Dăguci C, BaniTă IM. Effects of therapy with two combinations of antibiotics on the imbalance of MMP$2 \div$ TIMP-2 in chronic periodontitis. Rom J 
Morphol Embryol. 2015;56:77-83. PMID: 25826490.

24 Kumar MS, Vamsi G, Sripriya R, Sehgal PK. Expression of matrix metalloproteinases (MMP-8 and -9) in chronic periodontitis patients with and without diabetes mellitus. J Periodontol. 2006;77:1803-8. doi: 10.1902/ jop.2006.050293.

25 Chen D, Wang Q, Ma ZW, Chen FM, Chen Y, Xie GY, Wang QT, Wu ZF. MMP-2, MMP-9 and TIMP-2 gene polymorphisms in Chinese patients with generalized aggressive periodontitis. J Clin Periodontol.
2007;34:384-9. doi: 10.1111/j.1600051X.2007.01071.x.

26 Arpino V, Brock M, Gill SE. The role of TIMPs in regulation of extracellular matrix proteolysis. Matrix Biology. Matrix Biol. 2015;44-46:247-54. doi: 10.1016/j. matbio.2015.03.005.

27 Oyarzún A, Arancibia R, Hidalgo R, Peñafiel C, Cáceres M, González MJ, Martínez J, Smith PC. Involvement of MT1-MMP and TIMP-2 in human periodontal disease. Oral Dis. 2010;16:388-95. doi: 10.1111/j.16010825.2009.01651.x.

\section{Correspondence:}

Yongwei Li

Department of Stomatology, Hainan General

Hospital

19 Xiuhua Road

Haikou 570311 China

Phone: +86-898-68642645

liyongweihk@163.com

Received: July 29, 2018

Review: Sept 25, 2018

Accepted: Oct 26, 2018
Conflict of interest: none

Financial source: none
${ }^{1}$ Research performed at Central Laboratory, Hainan General Hospital, Haikou, China. 